\title{
Accumulation of plastics in terrestrial crop plants and its impact on the plant growth
}

\author{
Bhavika Garua, Jai Gopal Sharma* \\ Department of Biotechnology, Delhi Technological University, Delhi, India.
}

\section{ARTICLE INFO \\ Article history: \\ Received on: May 19, 2021 \\ Accepted on: July 24, 2021 \\ Available online: November 10, 2021}

\section{Key words:}

Agricultural ecosystem, microplastics, nanoplastics, terrestrial plants, crop plants.

\begin{abstract}
Small plastic particles are persistent in soil and will remain in the agricultural ecosystem for a long period, so there is an urgent need to uncover their potential impacts on the agricultural ecosystem. Plastics in the agricultural ecosystem are alarming as they can accumulate in crop plants and affect consumers by directly entering through the food web. Through disintegration of plastic, microplastics and nanoplastics (NPs) are generated and accumulated in significant quantities in soil. Incidentally, plastics have been shown to alter biophysical and geochemical properties of soil. The dispersion and transport of plastics in soil could directly impact crop plants and reduce crop yield. There are limited studies on uptake and accumulation of MPs and NPs in terrestrial plants but studies reported so far have shown phytoremediation as a potential remediation technique to extract and degrade plastic particles from agricultural soils. This review discusses the impacts of MPs and NPs on terrestrial plants growth and accumulation in different plant tissues based on recent literature.
\end{abstract}

\section{INTRODUCTION}

The properties which make plastic suitable for packing and production of goods - durable and resistant to environmental factors-also makes it almost impossible to eradicate from the environment completely. Various reports have claimed that most plastic materials disintegrate rather than degrade in the environment [1]. The global production of plastics increases every year. In 2019, world plastic production increased to 368 million metric as shown in Figure 1 [2].

These large plastics disintegrate into smaller fragments of size less than $5 \mathrm{~mm}$, referred as microplastics (MPs) [3]. Further deterioration of these microplastic fragments results in emergence of even smaller particles of size less than $0.1 \mu \mathrm{m}$, commonly called nanoplastics (NPs) [4]. The distinct sizes of plastics, MPs and NPs, are still unknown. Different authors define MPs and NPs differently. MPs are generally defined as particles in the size range of nanometer (100 nm-5 mm), along with sub-micrometer (100 $\mathrm{nm}-1 \mu \mathrm{m})$ and micrometer $(1 \mu \mathrm{m}-5 \mathrm{~mm})$ plastics, and NPs in the range of $1 \mathrm{~nm}-100 \mathrm{~nm}$.

*Corresponding Author

Jai Gopal Sharma, Department of Biotechnology, Delhi Technological

University, Delhi, India.E-mail: sharmajaigopal @dce.ac.in
Plastics in the ocean have drawn considerable attention in the last decade. Marine pollution has shown its effects in aquatic ecosystem and is evident to public. Extensive research have been done on assimilation of MPs and NPs by marine organisms $[5,6]$. Study on transport of small plastic particles beyond the gut of the organisms, entering the food web and transfer between trophic levels is still in its initial stage. While the fate of plastics in marine ecosystem is being progressively well studied, behavior of MPs and NPs in terrestrial environment is somewhat obscure, especially in agricultural ecosystem [7]. Critical limits for plastic contamination in soil are rarely defined so far which makes it harder to evaluate the bearing capacity of agricultural ecosystems [8]. Whether terrestrial plants can accumulate MPs and NPs and if so then how these can affect their growth and consequently enter the food chain, are two crucial problems of paramount importance to study the effects of plastics on terrestrial crop plants [9].

Recent studies have observed the origin and fate of these plastic fragments in terrestrial ecosystem especially in terrestrial crop plants (Table 1) $[10,11]$. The occurrence of different plastic materials has clinched much attention in marine environments, and its related shoreline. However, the terrestrial ecosystems are not much reviewed and studied for occurrence of plastics and their detrimental effects. Therefore, we present here a review on the 


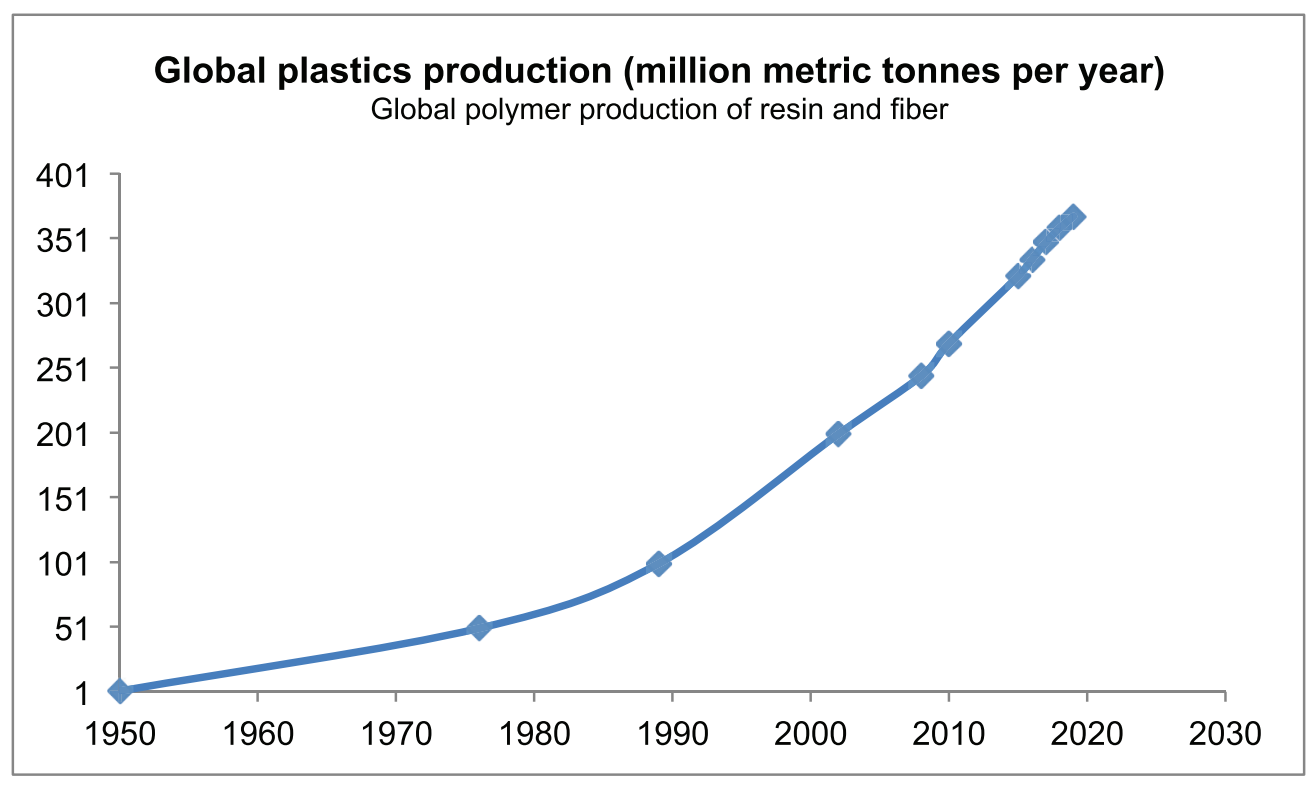

Figure 1. Plastic production from 1950 in million tons.

uptake and accumulation of plastic particles in terrestrial plants, along with its detrimental effects on their growth and yield in agricultural ecosystems.

\section{OCCURRENCE AND EFFECT OF PLASTIC PARTICLES ON SOIL QUALITY AND SURROUNDINGS}

Terrestrial ecosystem gets all sizes of plastic wastes from plastic mulch film, municipal solid waste bio solids, and plastic-coated fertilizers in soil and atmospheric deposition. Agricultural plastics such as plastic mulch films have advantages and disadvantages. Plastic mulch films used in agriculture are mostly preferred for cultivating specific crops as they help in modifying soil temperatures, maintaining soil moistures, and improving crop productivity within the soil [12]. The most commonly used plastic mulch is low-density polyethylene (LDPE) as it is inexpensive, easy processed, durable, and flexible [13]. The widespread application of these plastic mulches has contaminated soils because they are not entirely removed from the field and remains in the soil in the form of small chunks for decades. The plastic mulch films retained within the soil gradually breakdown into smaller particles [14], resulting in pollution of MPs and NPs. Use of nondegradable LDPE mulches in agriculture is observed extensively for its high stability, but these mulches increase accumulation of plastic wastes in agricultural ecosystem. Mulch fragments can negatively affect soil density.

The sludge is being used directly as a common source of fertilizer in agricultural soils which are concentrated with contaminants like plastic materials [15]. Plastic fibers are found in wastewater from washing clothes as well as microplastic beads from cosmetic and skin care products [16]. The sewage sludge contains around $80 \%-$ $90 \%$ of plastic particles and even after treatment, some amount of plastic still persists in sewage [17]. Studies have reported that plastic fragments retain in agricultural fields up to 15 years [15]. A notable contributor for plastic pollution in soils can be landfills, urban and industrial centers that directly input plastic fragments on land through improper waste disposal, accidental loss, and contamination by soils and aerosols [18]. The contamination by various other soils, like paddy soils and coastal soils [19], plays a crucial role because of the atmospheric particles which can be quickly transported across various distances and contaminates the environment by disintegration of various large plastic fragments into smaller chunks of microplastic and NPs. A significant source of plastic contamination in soil can also be attributed to atmospheric deposition. Moreover, plastic use in irrigation and distribution systems is very common in agricultural fields. As other plastic tends to degrade into smaller particles by environmental factors and application of chemicals in agriculture, these plastic pipes are also subjected to breakdown in a much similar way.

Degradation and fragmentation of plastic occur on soil surface and get transported to other ecosystems like fresh water. Once fragmentation of plastic starts in the upper layer of soil, it sinks to deeper layers, where physical factors like low temperature and less oxygen availability causes decrease in biodegradation rates. As plastic mulches are used repetitively, the amount of fragments increases crop by crop in fields which consequently decreases crop yield [20]. The constituents of plastics, mainly additives like plasticizers, are harmful for agricultural ecosystems. When plastic mulch comes in contact with water, fertilizers and pesticides, its compounds leach into the soil underneath. Phthalate esters (PAEs) leach out from films into the soil and further are absorbed by plants. So with plastic fragments, these chemical compounds also accumulate in soil [20]. The continuous use of plastic films has left residual plastic film particles in farm soil affecting infiltration of water and nutrients into the soil [21]. Soil structure is lost when larger quantities of plastic particles remain in it for a longer time as shown in Figure 2. These plastic particles can obstruct the water infiltration and affect the water holding capacity of soil by blocking soil pores. This can further lead to lesser amount of oxygen in soil 
Table 1. Recent studies reported on impacts of MPs and NPs on terrestrial plants.

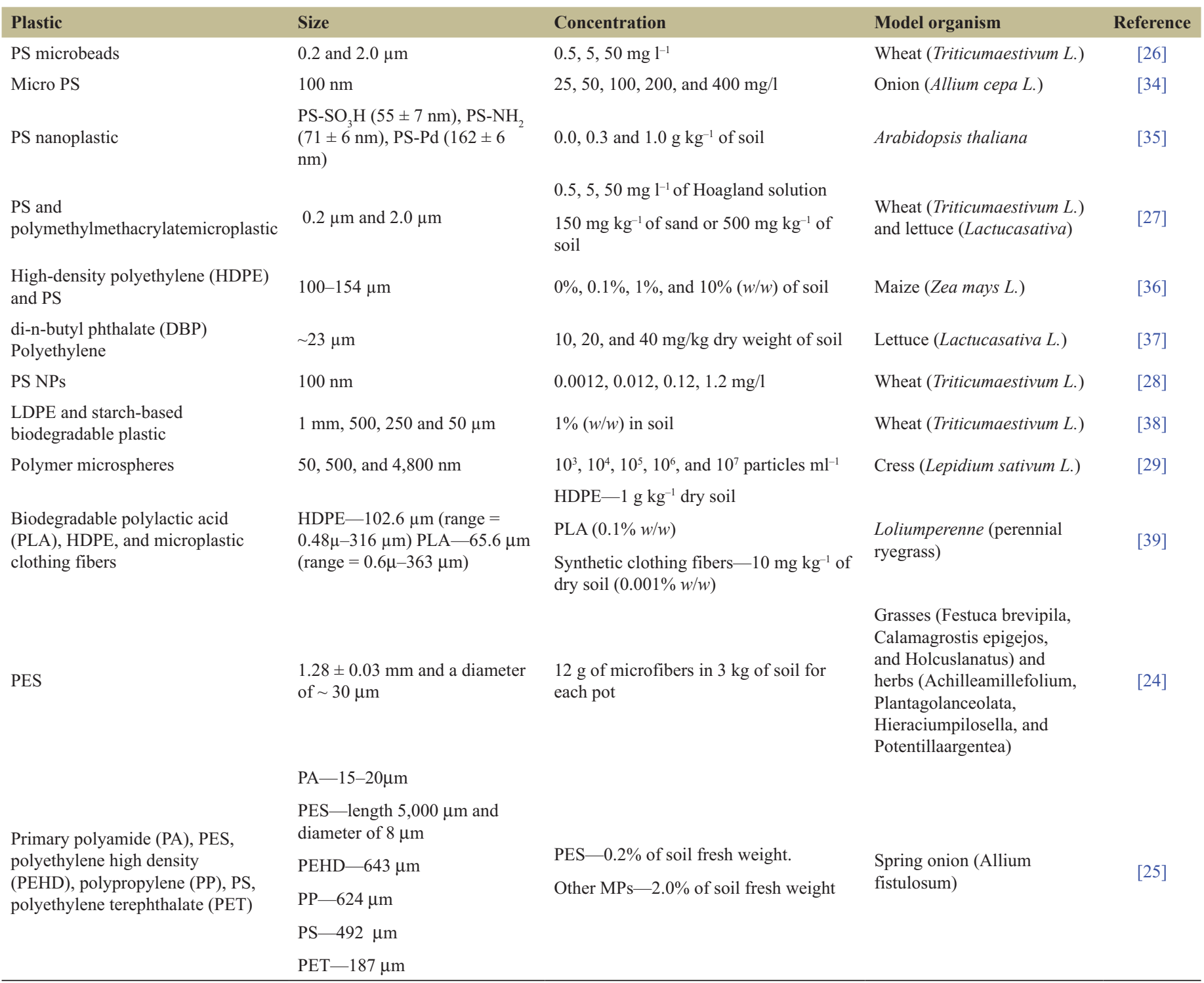

and ultimately leading to anoxia [8] and can affect nitrogen cycling and soil organic carbon [22]. Plastics affect crucial soil parameters such as soil bulk density, water holding capacity and soil structure $[23,24]$. De Souza MacHado et al. [10]showed that plastic fibers of polyester, polyacrylic, and polyethylene decreased the soil bulk density and microbial activity of the soil. They explained the alteration in soil density as a consequence of plastics being less dense than minerals naturally present in soils. The water holding capacity was also majorly affected by polyester fibers (PES) in a concentration dependent manner as compared to other plastic fibers. The effects of plastic fibers on soil structure and properties depend on the nature of plastics, shape and size of the particles. For example more flexible PES blend more homogeneously and entangle effectively with surrounding soil particles and these fibers can incorporate in soil clumps at finer scales affecting soil biophysical properties more than other plastic fibers [23].
Soil structure is lost when larger quantities of plastic particles remain in it for a longer time. These particles obstruct the water infiltration and affect the water holding capacity of soil. This can also further lead to a lesser amount of oxygen in soil ultimately leading to anoxia [8]. Addition of plastics in soil can affect nitrogen cycling and soil organic carbon. This increases nitrogen content in the soil, and further increases leaf nitrogen content [25]. Plastics can contribute to soil carbon content. Plastics are mostly carbon for example polystyrene (PS) and polyethylene are $90 \%$ carbon. When these plastics are introduced in agricultural soil, it breaks down into smaller particles and contributes to soil carbon storage [22].

\section{TRANSPORT OF MPS IN PLANT TISSUES}

Studies have shown translocation of plastics in plant tissues [26-29]. Probable ways of transport of nanoparticles of smaller 


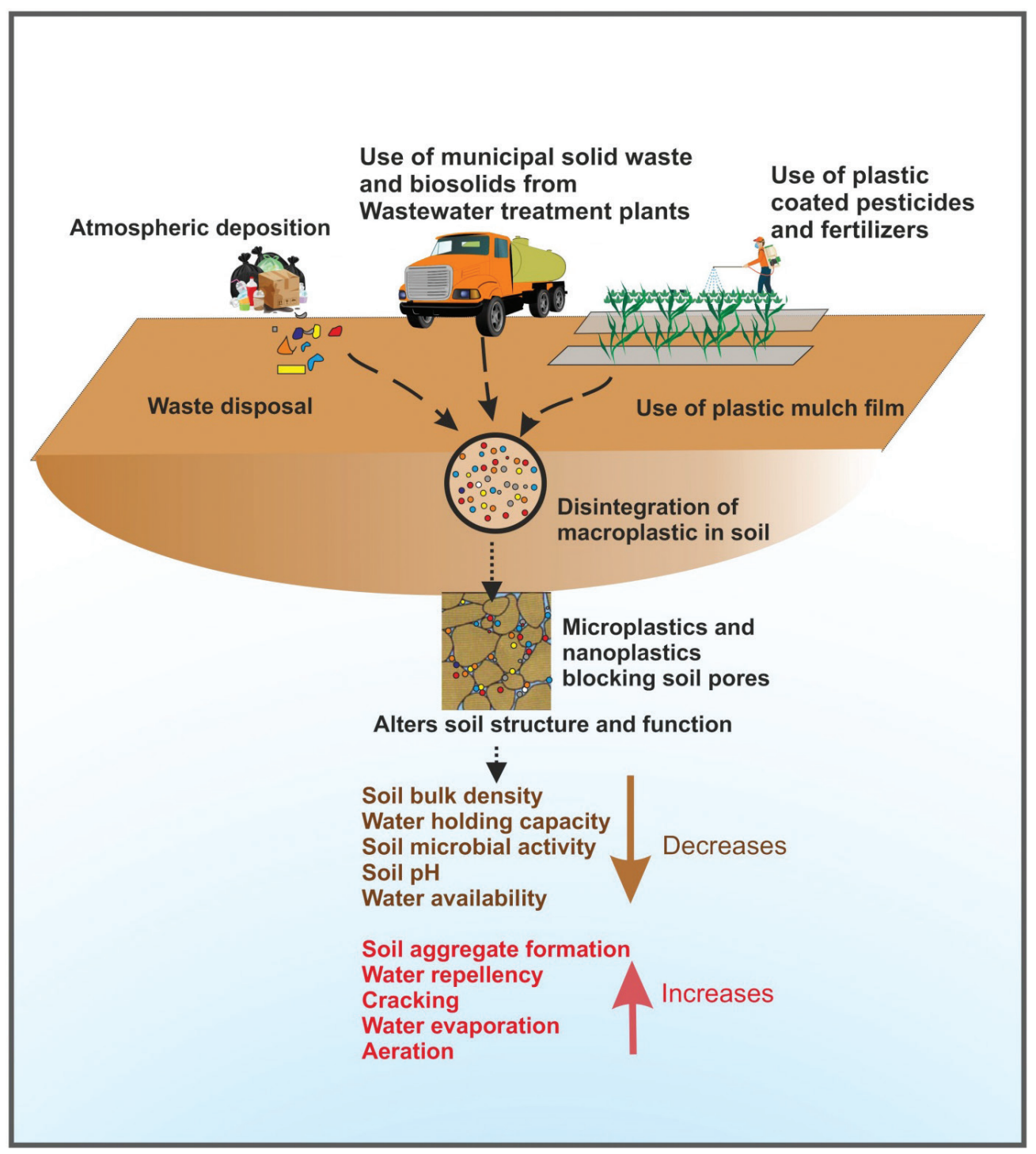

Figure 2. Impact of plastic contamination on soil properties.

sizes into plant cells are endocytosis, passive diffusion, facilitated diffusion, and translocation via plasmodesmata [30]. NPs gets transported into endodermis by capillary action and osmotic pressure [31]. Other nanoparticles can also transport with the help of membrane proteins through symplastic pathway and are taken up by cells directly through plasma membrane or via endocytosis [32]. On the other hand, intercellular transport of such particles is mediated by plasmodesmata connecting cells together [26,27]. The stomatal openings can also be a possible route for assimilation of nanoparticles which then get translocated through the xylem tissue [33].

\subsection{Effects of Plastic Particles on Seed Germination}

Presence of plastics in soil can cause reduction of seeds that germinate or can reduce the rate of germination (Fig. 3). The probable effects on seed germination can be due to leachates of plastics mixing with water which seeds imbibe during germination or due to change in soil structure (Fig. 2) by smaller plastic particles especially micro and NPs [40]. The angiosperm seeds have testa, seed capsule, which controls germination and protects it from extreme surrounding environmental conditions [41]. The seed coat act as a barrier between surrounding environment and embryo, protecting it from contamination till radical starts developing. During germination, when seeds imbibe water from surrounding, they are prone to toxicants to enter through pores in seed capsule [42].

Boots et al. [39] studied effects of different MPs (biodegradable PLA, HDPE, and microplastic clothing fibers) on perennial ryegrass. They reported that plastics reduced the number of ryegrass seeds that germinated. They hypothesized that this reduction can be blockage of seed capsule by plastic particles. Another study conducted by Pflugmacher et al. [40] reported that the germination speed and as a consequence germination rate index of seeds of garden cress, L. sativum, got reduced when treated with polycarbonate granules and its leachates. Germination rate of seeds is measured by germination rate index which gives 


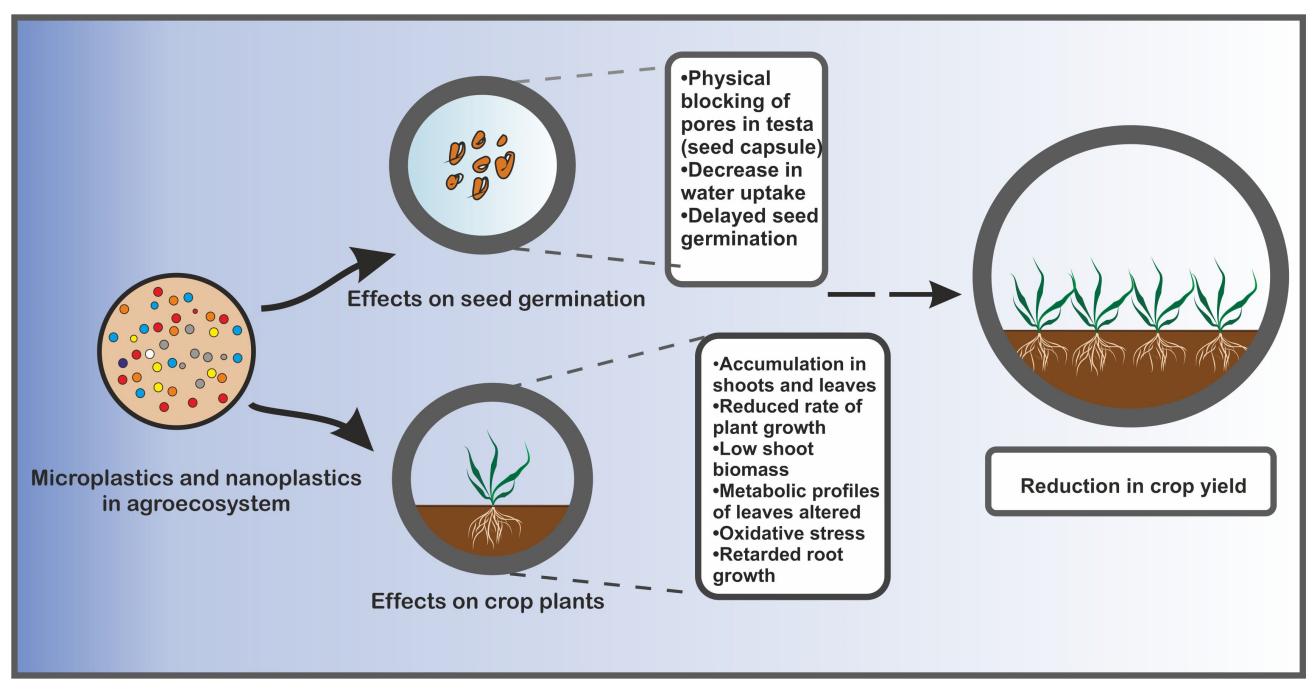

Figure 3. Effects of MPs and NPs on seed germination and plant growth.

the percentage of germination on each day of germination period [28]. The implication of this study can be that if too many plastic particles and their leachates gets mixed with agricultural soil then it can result in delayed growth and lesser germination rate index which can further affect crop yield [40].

Similar to the effects of NPs, MPs can also block pores in the seed capsules affecting water uptake and rate of germination. Later these microparticles can block root hairs affecting uptake of nutrients. Bosker et al. [29] also observed presence of fluorescent MPs on the surfaces during all the growth stages of $L$. sativum [29]. Therefore, plastic particles small enough to block pores on seed capsule can affect rate of seed germination resulting in lesser germinating seeds.

\subsection{Effects of Plastics on Vascular System}

No study as such has reported presence of MPs or NPs in vascular system of plants. No accumulation is observed in xylem or phloem [26]. Although the presence of aggregates of PS beads of size 0.2 $\mathrm{mm}$ in xylem and on cell wall of cortex tissue was observed in wheat root [27], the observation suggests that beads got transported through intercellular space through apoplastic pathway which is discussed in following section. Once the particles come inside the central cylinder, they move toward aerial parts of the plant through vascular system of xylem tissue in transpiration stream [28]. This transport resulted in plastic particles being transported from roots to stem and leaf vein vasculature. Although, with an increase in microbead size $(2.0,5,7$, and $10 \mu \mathrm{m})$, the transport of beads to peripheral parts of plants decreases [26].

\subsection{Effects of Plastics on Roots and Shoots}

In spite of the various studies on the uptake of nanomaterials by apoplastic transport, researchers have assumed that NPs cannot pass through the cell wall as physical barriers of plant tissue as these particles are too large to internalize into plant cells. Uptake of nanomaterials is possible by plant cells resulting in transport to different parts and accumulation in roots and shoots indicating same for plastics of nano size as shown in Figure $3[35,43]$. For example, confocal images of study conducted by Li et al. [26] substantiates increased accumulation of $0.2 \mu \mathrm{m}$ PS microbeads in roots, shoots, and leaves of wheat in concentration dependent manner. Moreover, studies have shown that MPs can affect root growth negatively and resulting in either reduction of root growth rate or reduction of root biomass. Exposure to smaller sized microplastic can also result in decrease of shoot height [39]. A similar observation was reported by Bosker et al. [29], that $50 \mathrm{~nm}$ polymer microspheres decreased root growth in L. sativum seedlings after 24 hour of exposure. The study also showed accumulation of MPs on root hair. A reduction in root growth was also observed by Kalčíková et al. [44], that polyethylene microbeads inhibited root growth for the aquatic duckweed species Lemna minor by mechanically blocking it and further reducing the root length. Exposure of micro PS to A. cepa also resulted in reduction of root growth in both dose and time dependent manner [34]. Reduction in root growth due to exposure to toxicant is directly correlated with the inhibition of apical meristem of root tips [45]. Reduction in root length in onion functions as a bioindicator of phytotoxicity of environmental pollutant. Similarly polyamide MPs can decrease root to leaf dry biomass ratio while increasing root length and decreasing root average diameter [25].

Li et al. [27] hypothesized transport of plastic particles into the plant roots via crack entry mode; entire lateral root cap and the root apical meristem of wheat and lettuce, further to shoots through apoplastic transport. The apoplast comprises all beyond the plasmalemma including intermicellar and interfibrillar space and xylem stretches to the rhizoplane and cuticle [46]. The Casparian band in root endodermis does not allow transport of water and chemicals into root stele and act as physical barrier. However, in areas where endodermal cells are not mature and at the secondary root initiation sites, this Casparian band is found discontinuous. Discontinuous areas where active cell division is observed in apical meristem can allow transport of plastics unhindered as these areas are entry points for plant pathogens known as crack entry mode [26]. 


\section{TOXIC EFFECTS OF PLASTICS ON SOIL HEALTH AND PLANT GROWTH}

Plant communities get affected rapidly to environmental toxicants in terms of evenness than richness on the basis of biomass and species abundance [24]. It can affect ecosystem by promoting growth of some plant species and decreasing others. As discussed above, plastics can change soil structure and properties as well as biophysical and geochemical environment affecting terrestrial plant growth in many ways [47]. The soil microbiota also gets altered in soil where toxicants are observed. All the above characteristics make up the soil ecosystem thus; the effects can be extrapolated to plant growth as well in agricultural ecosystem. Plastics in micro or nano size can enter in plant tissues and accumulate in cells through xylem affecting overall growth of the plant significantly.

A study showed effects of different plastics on soil properties and consequently the plant grown in it. The study by Anderson Abel de Souza Machado showed the effects of six different MPs (PES, polyamide beads, and four fragment types: polyethylene, polyester terephthalate, PP, and PS) on soil health and performance of spring onion (A. fistulosum). Soil structure was affected by all the type of plastics. Significant decrease in soil bulk density was observed in soils treated with all types of plastics. Water stable aggregate of soil decreased, whereas rhizosphere showed higher water stable aggregate. The property of water stable aggregate of soil is the ability to resist the change in properties by external forces like soil erosion and it depends on organic matter present in the soil [48]. The plants in soil decreased the water availability which in turn decreased microbial metabolic activity. The exposure to MPs of all type had nearly similar effects on plant roots. The root biomass increased with decrease in root diameter. The ratio of root to leaf dry biomass was increased. Nitrogen in leaf was increased. Polyamide microplastic beads are formed by polymerization of amines and carboxylic acids this can help to elucidate the increase in nitrogen content in plant tissues. Thus, remaining monomers interact loosely with the matrix and get released easily from it into the soil and act as fertilizer. This increases the nitrogen content in soil, and further in leaf nitrogen content, total biomass of plant and decrease in root to leaf dry biomass ratio. Similar pattern can be observed in other plastics which can also contribute to nitrogen content of soil like polyacrylonitrile and polyaramide while polytetrafluoroethylene can contribute fluor in soil [25]. In similar pattern, some of the plastics can also act as carbon storage in soil which can affect soil microbiome [22].

Studies have revealed that even the chemicals used in plastics are harmful for ecosystem if released in soil. Di(2-ethylhexyl) phthalate (DEHP) and DBP are phthalic acid esters which are artificially-synthesized industrial chemical, widely used for plastic production as plasticizer [49]. These chemicals can be released into the soil by weathering and disintegration of plastics. Gao et al. [37], reported that DBP and DEHP in soil can cause oxidative stress in wheat grain increasing reactive oxygen species. The DBP, DEHP, and their metabolites were found higher in grains than in stem, leaves and root of wheat crop.

Soils with sludge containing MPs fostered the growth of tomato plants, while delaying and diminished fruit production

\section{IMPLICATION OF PLANT-MPS INTERACTION}

Small plastic particles can enter marine and terrestrial environments in more than one way thus; consumption of plastics by humans is unavoidable. Plastic particles have low impact on growth of terrestrial plants but high absorption and accumulation in plant tissues can cause negative impact on ecosystem. A similar effect is possible in aquatic ecosystem, where accumulation of plastics in aquatic vascular plants could have implications on herbivore consumers but fewer detrimental effects on plant growth [50,51]. Thus, plastics can enter in food web through plants and get transferred to other trophic levels through consumers.

As discussed earlier, toxic compounds like additives from plastics used in agriculture runoff in soil due to pesticide exposure and breakdown. These compounds then absorb agrochemicals in soil affecting soil quality and microbiota. Plastics have harmful chemicals like bisphenol A, thalates, and poly- fluorinated chemicals etc can affect human and environment. The toxic compounds in plastics cause problems like vision failure, eye irritation, difficulty in breathing, respiratory problems, liver and lung problems, cancers, skin diseases, dizziness and headache, birth defects, reproductive, gastrointestinal, cardiovascular, genotoxic problems, etc [52].

Plastic mulching film used in agriculture increases PAEs in soil [53]. These PAEs are taken up by the food crops and there it gets accumulated posing great risk on consumers. PAEs have been reported to be present in vegetables, fruits, and grains $[54,55]$. One such crop which can take up such compounds is wheat crop. A study reported that PAE treated soil had DEHP as the dominant PAE compound in soil and wheat grain samples. Major risk group was found to be children in the community [53]. MPs and NPs are reported to be found in fruits and vegetables also. The data for the same is not available for the public. One such study showed that plastic particles are more concentrated in fruits than in vegetables [56]. The most concentrated fruit with plastic was found to be apples due to immense vascularization of the fruit pulp besides their greater size than vegetables. The complexity of their root system and age of the tree, which is about several years, as compared to the vegetable bearing plants also affected plastic concentration in fruits [56]. Thus, assimilation of plastics by crop plants is a gateway for plastic particles leading into the food web from where it gets transferred to other trophic levels.

\section{PLASTIC IMAGING: FACTOR LIMITING UNDERSTANDING OF PHYTOTOXICITY}

Some factors that limit the understanding of phytotoxicity of such smaller plastic particles can be lack of standardized detection methods that would help in tracking such smaller particles in the environment and in plant tissues as well. Traditional methods for detection of NPs are transmission electron microscopy (TEM) and scanning electron microscopy (SEM). TEM and SEM require extensive sample preparation which requires sample fixation. This limits the field of view for intracellular presence of MPs or NPs in real time. However, for intracellular imaging, SEM and TEM are suitable when plastics are fluorescently tagged. Imaging of fluorescently tagged micro and NPs provides high resolution and rapid results with plant tissues [26]. Another approach for imaging 
plant tissues can be confocal laser scanning microscopy (CLSM). CLSM does not require extensive sample preparation as required for SEM and TEM. The sample preparation for CLSM is simple and it allows viewing 3-D structures of the sample. Thus, CLSM is a powerful tool for imaging fluorescent specimens. The Widefield fluorescent microscope shows specimen blurry and collects fluorescence signals from areas above and below the area of focus lacking contrast [57].

There is a knowledge gap in understanding the pathways that MPs and NPs go through in nature and enter in cells. The pathway that allows particles like plastic to enter in plant cells where the cell wall is a major barrier is still unknown. Small sized particles can easily enter the cell wall due to their size being in nano and micro meters [30]. The study of such minute particles can be helpful for agriculture in formulating ecologically sound chemicals or nanoformulations. Moreover, development of nanosensor instruments can be helpful for detecting abiotic stress preparatory to affecting the crop yield. Nanotechnology can help build well equipped and high-tech agricultural fields with well developed nanotools [43].

\section{PHYTOEXTRACTION OF PLASTICS IN AGRICULTURAL SOILS}

Phytoremediation is a green technology where plants in association with microbiota help in remediating contaminants through degradation, stabilization (phytostabilization) or accumulation. One of such techniques which are phytoextraction can be used to remove micro and NPs from agricultural soils where plastic particles are absorbed from root system and transported to other plant parts. Several studies have shown uptake of MPs through root system, this can be advantageous for phytoextraction process in fields. One of the studies has also shown that microspheres of PS broke in aggregates due to transportation decreasing in cohesion which lead to PS degradation in cucumber leaves [58]. Similar aggregates have been seen in plants in vascular system which shows uptake and degradation in terrestrial plants. This process can curb the transport of plastics into lower soil layers and groundwater and also decreases the bioavailability of the plastics in fields. Another way of remediation can be phytofiltration, where contaminants are filtered out from water by adhering to plant roots. Some reports where the study is conducted in Hoagland solution have shown that plastic particles adhered to root hair if not taken up by plants [29]. This process can help in removal of plastics by filtration, decreasing the plastic pollution. Furthermore, studies are needed for better and efficient extraction of plastics through plants from soil.

\section{CONCLUSION AND FUTURE PROSPECTS}

Interestingly, the low impact of micro and NPs on terrestrial plants and its assimilation and accumulation may have a wide range of ecological repercussions. On the other hand, this interaction has potential phytoremediation benefits. MPs and NPs can be removed through remediation techniques like phytoextraction, phytostabilization, and phytofiltration. Similar viewpoint has been hypothesized for aquatic vascular plants $[50,59,60]$ and microbial remediation of plastics present in soil $[61,62,63]$.
With continuous use of plastics in different fields, many new technologies have been introduced making plastics more durable which will further increase plastics in the ecosystem and ecological risks from its pollution. The research of presence of plastics in the agricultural ecosystem and underlying mechanism of uptake by crop plants is still in its infancy. This information can help in understanding of the extent of long-term exposure and future studies on other crop plants. There are few research articles on the effects of MPs on crop plants grown in plastic contaminated soil. Thus, the amount of plastic that was exposed in such studies is based on a few papers. Future studies should address the accumulation and other effects on different food crops and their edible parts due to various plastic particles. On a wider scale, the number of plastics in the agricultural ecosystem is still under study. Establishing better analytical methods of monitoring and toxicity assessments of soil and terrestrial plants can enhance present understanding. For example, different methods for analyzing sizes of plastic present in soil and their effects on soil properties and thereafter plant growth. Considering plastics as a diverse group of contaminants will help in developing sampling, quantification and characterization techniques in higher plants. This understanding can help in development of management strategies for plastic pollution and emission curb to agricultural ecosystems and further to humans as consumers.

\section{AUTHOR CONTRIBUTIONS}

All authors made substantial contributions to conception and design, acquisition of data, or analysis and interpretation of data; took part in drafting the article or revising it critically for important intellectual content; agreed to submit to the current journal; gave final approval of the version to be published; and agree to be accountable for all aspects of the work. All the authors are eligible to be an author as per the international committee of medical journal editors (ICMJE) requirements/guidelines.

\section{FUNDING}

There is no funding to report.

\section{CONFLICTS OF INTEREST}

The authors report no financial or any other conflicts of interest in this work.

\section{ETHICAL APPROVALS}

Not applicable.

\section{REFERENCES}

1. Lambert S, Sinclair C, Boxall A. Occurrence, degradation, and effect of polymer-based materials in the environment. In: Whitacre D (ed.). Reviews of environmental contamination and toxicology, Cham, Switzerland, Springer International Publishing, pp 1-53, 2014.

2. Geyer R, Jambeck JR, Law KL. Production, use, and fate of all plastics ever made. Sci Adv 2017;3(7):25-9.

3. Mammo FK, Amoah ID, Gani KM, Pillay L, Ratha SK, Bux F, Kumari S. Microplastics in the environment: interactions with microbes and chemical contaminants. Sci Total Environ 2020;743:140518. 
4. Ng EL, Huerta Lwanga E, Eldridge SM, Johnston P, Hu HW, Geissen $\mathrm{V}$, et al. An overview of microplastic and nanoplastic pollution in agroecosystems. Sci Total Environ 2018;627:1377-88.

5. Galloway T, Cole M, Lewis C. Interactions of microplastic debris throughout the marine ecosystem. Nat Ecol Evol 2017;1(5):116.

6. Horton AA, Walton A, Spurgeon DJ, Lahive E, Svendsen C. Microplastics in freshwater and terrestrial environments: evaluating the current understanding to identify the knowledge gaps and future research priorities. Sci Total Environ 2017;586:127-41.

7. Zang H, Zhou J, Marshall MR, Chadwick DR, Wen Y, Jones DL. Microplastics in the agroecosystem: are they an emerging threat to the plant-soil system? Soil Biol Biochem 2020;148:107926.

8. Qi R, Jones DL, Li Z, Liu Q, Yan C. Behavior of microplastics and plastic film residues in the soil environment: a critical review. Sci Total Environ 2020;703:134722.

9. Zhu F, Zhu C, Wang C, Gu C. Occurrence and ecological impacts of microplastics in soil systems: a review. Bull Environ Contam Toxicol 2019;102(6):741-9.

10. de Souza Machado AA, Kloas W, Zarfl C, Hempel S, Rillig MC. Microplastics as an emerging threat to terrestrial ecosystems. Glob Change Biol 2018;24(4):1405-16.

11. Rillig MC, Lehmann A, de Souza Machado AA, Yang G. Microplastic effects on plants. New Phytol 2019;223(3):1066-70.

12. Kader MA, Senge M, Mojid MA, Ito K. Recent advances in mulching materials and methods for modifying soil environment. Soil Tillage Res 2017;168:155-66.

13. Kasirajan S, Ngouajio M. Polyethylene and biodegradable mulches for agricultural applications: a review. Agronomy Sustain Dev 2012;32(2):501-29.

14. Briassoulis D, Babou E, Hiskakis M, Kyrikou I. Analysis of longterm degradation behaviour of polyethylene mulching films with prooxidants under real cultivation and soil burial conditions. Environ Sci Pollut Res 2015;22(4):2584-98.

15. Corradini F, Meza P, Eguiluz R, Casado F, Huerta-Lwanga E, Geissen V. Evidence of microplastic accumulation in agricultural soils from sewage sludge disposal. Sci Total Environ 2019;671:411-20.

16. Mason SA, Garneau D, Sutton R, Chu Y, Ehmann K, Barnes J, et al. Microplastic pollution is widely detected in US municipal wastewater treatment plant effluent. Environ Pollut 2016;218:1045-54.

17. Keller AS, Jimenez-Martinez J, Mitrano DM. Transport of nano- and microplastic through unsaturated porous media from sewage sludge application. Environ Sci Technol 2020;54(2):911-20.

18. Rillig MC, Ingraffia R, de Souza Machado AA. Microplastic incorporation into soil in agroecosystems. Front Plant Sci 2017;8:1805.

19. Lv W, Zhou W, Lu S, Huang W, Yuan Q, Tian M, et al. Microplastic pollution in rice-fish co-culture system: a report of three farmland stations in Shanghai, China. Sci Total Environ 2019;652:1209-18.

20. Serrano-Ruiz H, Martin-Closas L, Pelacho AM. Biodegradable plastic mulches: impact on the agricultural biotic environment. Sci Total Environ 2021;750:141228.

21. Wang Z, Li X, Shi H, Li W, Yang W, Qin Y. Estimating the water characteristic curve for soil containing residual plastic film based on an improved pore-size distribution. Geoderma 2020;370:114341.

22. Rillig MC. Microplastic disguising as soil carbon storage. Environ Sci Technol 2018;52(11):6079-80.

23. de Souza MacHado AA, Lau CW, Till J, Kloas W, Lehmann A, Becker $\mathrm{R}$, et al. Impacts of microplastics on the soil biophysical environment. Environ Sci Technol 2018;52(17):9656-65.

24. Lozano YM, Rillig MC. Effects of microplastic fibers and drought on plant communities. Environ Sci Technol 2020;54(10):6166-73.

25. de Souza Machado AA, Lau CW, Kloas W, Bergmann J, Bachelier JB, Faltin E, et al. Microplastics can change soil properties and affect plant performance. Environ Sci Technol 2019;53(10):6044-52.

26. Li L, Luo Y, Peijnenburg WJGM, Li R, Yang J, Zhou Q. Confocal measurement of microplastics uptake by plants. MethodsX 2020;7:100750.
27. Li L, Luo Y, Li R, Zhou Q, Peijnenburg WJGM, Yin N, et al. Effective uptake of submicrometre plastics by crop plants via a crack-entry mode. Nat Sustainabilty 2020;3(11):929-37.

28. Lian J, Wu J, Xiong H, Zeb A, Yang T, Su X, et al. Impact of polystyrene nanoplastics (PSNPs) on seed germination and seedling growth of wheat (Triticum aestivum L.). J Hazard Mater 2020;385:121620.

29. Bosker T, Bouwman LJ, Brun NR, Behrens P, Vijver MG. Microplastics accumulate on pores in seed capsule and delay germination and root growth of the terrestrial vascular plant Lepidium sativum. Chemosphere 2019;226:774-81.

30. Maity S, Pramanick K. Perspectives and challenges of micro/ nanoplastics-induced toxicity with special reference to phytotoxicity. Glob Change Biol 2020;26(6):3241-50.

31. Lin S, Reppert J, Hu Q, Hudson JS, Reid ML, Ratnikova TA, et al. Uptake, translocation, and transmission of carbon nanomaterials in rice plants. Small 2009;5(10):1128-32.

32. Tripathi DK, Singh S, Singh S, Srivastava PK, Singh VP, Singh S, et al. Nitric oxide alleviates silver nanoparticles (AgNps)-induced phytotoxicity in Pisum sativum seedlings. Plant Physiol Biochem 2017;110:167-77.

33. Hong J, Peralta-Videa JR, Rico C, Sahi S, Viveros MN, Bartonjo J, et al. Evidence of translocation and physiological impacts of foliar applied $\mathrm{CeO} 2$ nanoparticles on cucumber (Cucumis sativus) plants. Environ Sci Technol 2014;48(8):4376-85.

34. Maity S, Chatterjee A, Guchhait R, De S, Pramanick K. Cytogenotoxic potential of a hazardous material, polystyrene microparticles on Allium cepa L. J Hazard Mater 2020;385:121560.

35. Sun XD, Yuan XZ, Jia YB, Feng LJ, Zhu FP, Dong SS, et al. Differentially charged nanoplastics demonstrate distinct accumulation in Arabidopsis thaliana. Nat Nanotechnol 2020;15(9):755-60.

36. Wang F, Zhang X, Zhang S, Zhang S, Adams CA, Sun Y. Effects of co-contamination of microplastics and $\mathrm{Cd}$ on plant growth and $\mathrm{Cd}$ accumulation. Toxics 2020;8(2):36.

37. Gao M, Xu Y, Dong Y, Song Z, Liu Y. Accumulation and metabolism of di(n-butyl) phthalate (DBP) and di(2-ethylhexyl) phthalate (DEHP) in mature wheat tissues and their effects on detoxification and the antioxidant system in grain. Sci Total Environ 2019;697:133981.

38. Qi Y, Yang X, Pelaez AM, Huerta Lwanga E, Beriot N, Gertsen H, et al. Macro- and micro- plastics in soil-plant system: effects of plastic mulch film residues on wheat (Triticum aestivum) growth. Sci Total Environ 2018;645:1048-56.

39. Boots B, Russell CW, Green DS. Effects of microplastics in soil ecosystems: above and below ground. Environ Sci Technol 2019;53(19):11496-506.

40. Pflugmacher S, Sulek A, Mader H, Heo J, Noh JH, Penttinen OP, et al. The influence of new and artificial aged microplastic and leachates on the germination of Lepidium sativum L. Plants 2020;9(3):339.

41. Debeaujon I, Léon-Kloosterziel KM, Koornneef M. Influence of the testa on seed dormancy, germination, and longevity in Arabidopsis. Plant Physiol 2000;122(2):403-14.

42. Coen O, Magnani E. Seed coat thickness in the evolution of angiosperms. Cell Mol Life Sci 2018;75(14):2509-18.

43. Rajput V, Minkina T, Mazarji M, Shende S, Sushkova S, Mandzhieva $\mathrm{S}$, et al. Accumulation of nanoparticles in the soil-plant systems and their effects on human health. Ann Agric Sci 2020;65(2):137-43.

44. Kalčíková G, Žgajnar Gotvajn A, Kladnik A, Jemec A. Impact of polyethylene microbeads on the floating freshwater plant duckweed Lemna minor. Environ Pollut 2017;230:1108-15.

45. d'Aquino L, de Pinto MC, Nardi L, Morgana M, Tommasi F. Effect of some light rare earth elements on seed germination, seedling growth and antioxidant metabolism in Triticum durum. Chemosphere 2009;75(7):900-5.

46. Sattelmacher B. The apoplast and its significance for plant mineral nutrition. New Phytol 2009;182(1);284.

47. Khalid N, Aqeel M, Noman A. Microplastics could be a threat to plants in terrestrial systems directly or indirectly. Environ Pollut 2020;267:115653. 
48. Tisdall JM, Oades JM. Organic matter and water-stable aggregates in soils. Eur J Soil Sci 1982;33:141-63.

49. Gao M, Liu Y, Dong Y, Song Z. Photosynthetic and antioxidant response of wheat to di(2-ethylhexyl) phthalate (DEHP) contamination in the soil. Chemosphere 2018;209:258-67.

50. Kalč́ková G. Aquatic vascular plants - a forgotten piece of nature in microplastic research. Environ Pollut 2020;262:114354.

51. Gutow L, Eckerlebe A, Giménez L, Saborowski R. Experimental evaluation of seaweeds as a vector for microplastics into marine food webs. Environ Sci Technol 2016;50(2):915-23.

52. Proshad R, Kormoker T, Islam MS, Haque MA, Rahman MM, Mithu MMR. Toxic effects of plastic on human health and environment : a consequences of health risk assessment in Bangladesh. Int J Health 2017;6(1):1

53. Shi M, Sun Y, Wang Z, He G, Quan H, He H. Plastic film mulching increased the accumulation and human health risks of phthalate esters in wheat grains. Environ Pollut 2019;250:1-7.

54. Mo CH, Cai QY, Tang SR, Zeng QY, Wu QT. Polycyclic aromatic hydrocarbons and phthalic acid esters in vegetables from nine farms of the Pearl River Delta, South China. Arch Environ Contam Toxicol 2009;56(2):181-9.

55. Fu X, Du Q. Uptake of Di-(2-ethylhexyl) phthalate of vegetables from plastic film greenhouses. J Agric Food Chem 2011;59(21):11585-8.

56. Conti GO, Ferrante M, Banni M, Favara C, Nicolosi I, Cristaldi A, et al. Micro- and nano-plastics in edible fruit and vegetables. The first diet risks assessment for the general population. Environ Res 2020;187:109677.

57. Smith CL. Basic confocal microscopy. Curr Protoc Neurosci 2011;56(1):1-18.

58. Sun XD, Yuan XZ, Jia Y, Feng LJ, Zhu FP, Dong SS. Differentially charged nanoplastics demonstrate distinct accumulation in Arabidopsis thaliana. Nat Nanotechnol 2020;15(9):755-60.
59. Ekperusi AO, Sikoki FD, Nwachukwu EO. Application of common duckweed (Lemna minor) in phytoremediation of chemicals in the environment: state and future perspective. Chemosphere 2019;223:285-309.

60. Rezania S, Taib SM, Md Din MF, Dahalan FA, Kamyab H. Comprehensive review on phytotechnology: heavy metals removal by diverse aquatic plants species from wastewater. J Hazard Mater 2016;318:587-99.

61. Tiwari N, Santhiya D, Sharma J.G. Microbial remediation of micronano plastics: Current knowledge and future trends. Environmental Pollution. 2020; 265(Part A): 115044.

62. Tiwari N, Garua B and Sharma J.G. Microbial diversity, interactions, and biodegradation/biotransformation of organic and inorganic contaminants. In Maulin P. Shah, Susana Rodriguez-Couto. Wastewater Treatment Reactors. Elsevier; 2021;341-72.

63. Tiwari N, Bansal M, Sharma J.G. Metagenomics: A powerful lens viewing the microbial world. In Maulin P. Shah, Susana RodriguezCouto. Wastewater Treatment Reactors Elsevier; 2021;309-39.

\section{How to cite this article:}

Garua B, Sharma JG. Accumulation of plastics in terrestrial crop plants and its impact on the plant growth. J Appl Biol Biotech 2021; 9(06):25-33. 